\title{
Chronic Bacterial Prostatitis in a Turkish Population: The Microbiological Etiology and Distribution
}

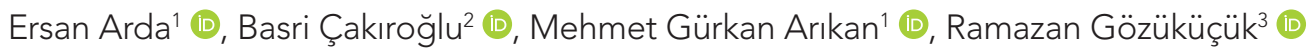 \\ ${ }^{1}$ Department of Urology, Trakya University School of Medicine, Edirne, Turkey \\ ${ }^{2}$ Clinic of Urology, Hisar Hospital Intercontinental, İstanbul, Turkey \\ ${ }^{3} \mathrm{Clinic}$ of Infectious Diseases and Clinical Microbiology, Hisar Hospital Intercontinental, İstanbul, Turkey
}

Cite this article as: Arda E, Çakıroğlu B, Arıkan MG, Gözüküçük R. Chronic bacterial prostatitis in a Turkish Population: The Microbiological Etiology and Distribution. JAREM 2018; 8(3): 153-6.

\begin{abstract}
Objective: To investigate the category 2 frequency and microorganism distribution of patients diagnosed with chronic prostatitis in a Turkish population.

Methods: Data of 3200 patients diagnosed with chronic prostatitis in the urology outpatient clinic between 2009 and 2014 were retrospectively reviewed. The symptom scores were calculated considering the National Institutes of Health-Chronic Prostatitis Symptom Index (NIH-CPSI) according to pain (0-21 points), quality of life (0-12 points), and urinary (0-10 points) subdomains to a total score of 0-43 points. All patients were checked for symptoms, urinalysis, expressed prostatic secretion (EPS), or urine after prostatic massage (VB3) culture and PCR (Polymerase Chain Reaction) of EPS or VB3 for Chlamydia trachomatis, Ureaplasma urealyticum, Mycoplasma hominis, Mycoplasma genitalium, and Trichomonas vaginalis.

Results: The mean age of the patients was calculated as 37.7 \pm 7.4 (range 22-65) years. The average of total NIH-CPSI score was determined as 9.08 (range 1-40). In 223 of 3200 patients, positive culture and/or PCR results were observed. The results were as follows: E. coli 27 (12.1\%), E. faecalis 18 (8.1\%), S. epidermidis 15 (6.7\%), S. haemolyticus 10 (4.5\%), S. aureus 5 (2.2\%), S. agalactiae 4 (1.8\%), Pseudomonas $3(1.3 \%)$, C. trachomatis $24(10.8 \%)$, U. urealyticum $95(42.6 \%)$, M. genitalium $6(2.7 \%)$, M. hominis $14(6.3 \%)$, and T. vaginalis $2(0.9 \%)$.

Conclusion: In a Turkish population, category 2 patients constitute $7 \%$ of all chronic prostatitis patients. This ratio is consistent with the NIH classification of prostatitis data, but it differs etiologically with $U$. urealyticum, E. coli, and C. trachomatis being the most proliferated pathogens in our study.

Keywords: Chronic bacterial prostatitis, diagnosis, etiology, infection, prostate
\end{abstract}

ORCID IDs of the authors: E.A. 0000-0002-5430-6561; B.Ç. 0000-0002-1047-1629; M.G.A. 0000-0002-9707-596X; R.G. 0000-0002-8205-4752.

\section{INTRODUCTION}

Prostatitis has been identified as a disease that is proven by microscopy and culture of expressed prostatic secretion (EPS) (1). And according to Meares and Stamey (2), it is diagnosed with clinical symptoms and findings. In the United States, $8 \%$ of the patients who are referred to the urology clinics receive a prostatitis diagnosis (3). Many studies have revealed the risk factors that increase the prevalence of recurrent prostatitis, such as lifestyle, diet, cigarettes, and gastrointestinal-anorectal diseases $(4,5)$. The term "prostatitis syndrome" covers the conditions that affect the prostate together with sexual function disorders, clinical urethral symptoms, prostatic symptoms, and other symptoms (6). Symptoms are defined according to their duration as acute or, in case of continuation for at least 3 months, chronic prostatitis (6). The classification of prostatitis depends on the patient's clinical complaints or the presence of bacteria or leukocytes in the EPS
(7). The National Institutes of Health (NIH) categorizes prostatitis syndrome into four different types: Type 1: acute bacterial prostatitis, Type 2: chronic bacterial prostatitis (CBP), Type 3: chronic non-bacterial prostatitis or chronic pelvic pain syndrome (CPPS), and Type 4: asymptomatic inflammatory prostatitis (1).

Chronic bacterial prostatitis has been reported in 3\%-10\% according to the $\mathrm{NIH}$ classification of prostatitis data (8). It is the most prevalent urologic disease in men $<50$ years and the third most prevalent urologic disease in men $>50$ years after benign prostate hyperplasia and prostate cancer (9). However, there are just a few studies in which the factors that cause CBP are examined.

The aim of the present study was to research the frequency of category 2 of chronic prostatitis patients (CBP) in a Turkish society and the distribution of agents that play a role in patients' etiology. 


\section{METHODS}

Between 2009 and 2014, data of 3200 patients applying to the urology outpatient clinic who received a CBP diagnosis were retrospectively examined. All patients gave written consent, and the study was conducted in accordance with the Declaration of Helsinki.

Inclusion criteria were the presence of symptoms related to chronic prostatitis for at least 3 months according to the $\mathrm{NIH}$ classification guidelines and a positive Meares and Stamey (M\&S) (2) four-glass test (10). We used the term positive M\&S test for all tests in which bacterial load in EPS or in post-prostate massage urine (VB3) is at least 1000 colony-forming units per milliliter and at least 10 times higher than in the first void early morning urine (VB1) and midstream urine (VB2). All patients were symptomatic according to the Italian version of the $\mathrm{NIH}$-Chronic Prostatitis Symptom Index (CPSI) with a cut-off for symptomatic CBP of 15. Patients < 18 years; affected by major concomitant diseases; with urethral strictures, acute urethritis with urethral discharge, or neurological bladder voiding disturbances were excluded (11). Furthermore, all patients positive to cytological urine analysis or who had previously undergone prostate surgery or who had undergone antibiotics for 4 weeks prior to the study were also excluded. All patients with more than one isolated bacteria or positive to tests for Chlamydia trachomatis, Trichomonas vaginalis, Mycoplasma genitalium, Neisseria gonorrhoeae, herpes simplex virus, and human papillomavirus were also excluded. Moreover, in order to exclude all patients with urethritis resulting from $C$. trachomatis infections, each patient underwent a urethral swab.

The symptom scores of all the patients were calculated out of a total of 43 points, considering the $\mathrm{NIH}$-CPSI according to the subgroups of pain (0-21 points), quality of life (0-12 points), and urinary symptoms (0-10 points). Patients were separated into three groups according to their symptom scores on the $\mathrm{NIH}-\mathrm{CPSI}$ index as severe (>29), moderate (16-29), and mild dysfunction (015).

The four-glass test was implemented on patients who were likely to have CP/CPPS to localize the lower urinary tract infections. Specimens were acquired in the shape of: (1) the VB1 (first voided urine) that is approximately $10 \mathrm{ml}$ and is used to provide information about urethral colonization, (2) the VB2 (midstream urine) that is used for middle and late sampling, (3) the EPS that expresses prostate secretion, and (4) the VB3 that is the first $10 \mathrm{ml}$ of urine obtained after a prostate massage.

The four-glass test specimens were evaluated using direct microscopy and standard microbiological methods (Blood Agar and MacConkey Agar), and the PCR was also analyzed using the EPS or VB3 sample.

\section{RESULTS}

The average age of the patients was calculated as $37.7 \pm 7.4$ (distribution of 22-65) years. The average of total NIH-CPSI score was calculated as 9.08 (distribution of 1-40) according to the subgroups of pain (0-21 points), quality of life (0-12 points), and urinary symptoms (0-10 points) (Table 1$)$.

The NIH-CPSI severity was categorized as mild (0-15 points), moderate (16-29 points), and severe (>29 points) dysfunction with 134 (60\%), 67 (30\%), and 22 (10\%) patients in each group, respectively. According to that, the frequency of chronic prostatitis category 2 was calculated as $7 \%$.

Of the 3200 patients who were retrospectively scanned with cell culture and/or PCR method, reproduction and/or affirmative test results were determined in 223 of them. The ranking and distribution of pathogens, which were reproduced and/or whose PCR analysis was positive, have been summarized in Table 2 according to all acquired results.

\section{DISCUSSION}

Chronic bacterial prostatitis is responsible for 3\%-4\% of all cases of prostatitis (12). Together with Escherichia coli, which is the most important etiological factor, it was identified that Grampositive microorganisms, such as Staphylococcus saprophyticus, Staphylococcus aureus, Staphylococcus epidermidis, U. urealyticum, and C. trachomatis, also played a role in the etiology (12). As a result of medical history and physical examination, if prostatitis is suspected, the four-glass test as defined by Meares and Stamey (2) has become the gold standard test for diagnosis (13). Owing to patients' discomfort and the strength of its clinical application, Nickel et al. (14) revealed a simpler two-glass scanning test to evaluate inflammation and infection, in which the prostatic fluid was collected before and after the prostatic massage.

In a study by Lobel and Rodriquez (15), pathogenic microorganisms related to possible prostatitis were separated into five categories and identified as: (1) prostate pathogens that are commonly accepted, including Gram-negative bacteria: Enterobacteriaceae (e.g., Escherichia, Klebsiella, and Pseudomonas); (2) possible prostate pathogens, including Gram-positive bacteria (e.g., Enterococcus and Staphylococcus); (3) possible prostate pathogens, such as coagulase-negative Staphylococcus, Chlamydia, Mycoplasma, anaerobic bacteria, yeast (Candida), and Trichomonas; (4) commonly known extraprostatic pathogens, such as Lactobacillus and Corynebacterium; and (5) biofilms, viruses, and cell wall deficient bacteria which cannot be reproduced in cultures.

In another study, based on 332 patients diagnosed with CBP, the two most identified agents in the EPS culture of 23 (44.3\%) cases were Enterococcus faecalis and E. coli which was similar to our study (16). Despite that, the proportional excess of bacteria, which were reproduced in the cell culture, and the determination of a high ratio of $E$. faecalis are becoming dissimilar.

Ouzounova-Raykova et al. (17) examined the EPS of 98 patients between the ages of 23 and 66 years, where C. trachomatis positivity was found in three PCR analyzed samples, in which meanwhile cell culture positivity was determined in two of these three samples. They reported that PCR analysis, in the determination of $C$. trachomatis as a CBP factor, is a more sensitive method than cell culture. Despite the view being supported that PCR is a more sensitive method, our study, which had the same average of age, differed with a higher detection rate of $10.8 \%$. Nevertheless, many studies have revealed that the PCR method is at a high sensitivity for C. trachomatis (18).

In different studies that examined the factors causing CBP, it has been proven that Mycoplasma similar to Ureaplasma spp., Myco- 
Table 1. Subgroup values of NIH-CPSI groups in patients with chronic prostatitis

\begin{tabular}{|l|c|c|c|}
\hline NIH-CPSI scores & Urinary & Pain & QoL \\
\hline Mild dysfunction & $3.13 \pm 2.54$ & $2.64 \pm 3.03$ & $1.63 \pm 1.35$ \\
\hline Moderate dysfunction & $4.79 \pm 3.12$ & $11.37 \pm 3.83$ & $5.27 \pm 1.80$ \\
\hline Severe dysfunction & $6.20 \pm 5.70$ & $21.20 \pm 0.75$ & $10.40 \pm 1.20$ \\
\hline
\end{tabular}

Table 2. Ranking and distribution of pathogens reproducing in the cell culture and/or are PCR positive

\begin{tabular}{|c|c|c|c|}
\hline & Pathogen & $\begin{array}{l}\text { No. } \\
\text { (n) }\end{array}$ & $\begin{array}{l}\text { Percentage } \\
\text { (\%) }\end{array}$ \\
\hline \multirow{8}{*}{ 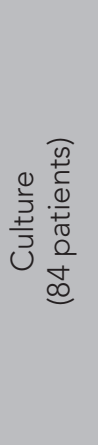 } & Escherichia coli & 27 & 12.1 \\
\hline & Enterococcus faecalis & 18 & 8.1 \\
\hline & Staphylococcus epidermidis & 15 & 6.7 \\
\hline & Staphylococcus haemolyticus & 10 & 4.5 \\
\hline & Staphylococcus aureus & 5 & 2.2 \\
\hline & Streptococcus agalactiae & 4 & 1.8 \\
\hline & Pseudomonas & 3 & 1.3 \\
\hline & Trichomonas vaginalis & 2 & 0.9 \\
\hline \multirow{4}{*}{ 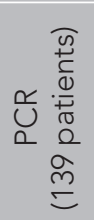 } & Chlamydia trachomatis & 24 & 10.8 \\
\hline & Ureaplasma urealyticum & 95 & 42.6 \\
\hline & Mycoplasma genitalium & 6 & 2.7 \\
\hline & Mycoplasma hominis & 14 & 6.3 \\
\hline \multicolumn{4}{|c|}{ PCR: polymerase chain reaction } \\
\hline
\end{tabular}

plasma hominis, and M. genitalium actually colonize the genital system $(19,20)$. For this reason, M. hominis has been reported to be much rarer causing genitourinary system infections in men than women based on anatomic adjacency (18). With the determination of M. hominis in only 14 (6.3\%) and Mycoplasma genitalium in $6(2.7 \%)$ of 139 patients diagnosed with chronic prostatitis, these findings were supported by our own PCR results.

Genital system colonization in both sexes for $U$. urealyticum is common, but the prevalence identified in the EPS sample has been reported to be between $10 \%$ and $40 \%$ (21). In addition, in different studies, it has been shown that $\mathrm{CBP}$ caused by $U$. urealyticum is frequently identified as asymptomatic $(20,22)$. Despite this, we observed that most of the $U$. urealyticum cases of our study were symptomatic with multilevels and varieties and differed with a high determination ratio of $42.6 \%$ in CBP.

In another study that included 105 patients in which hospitalacquired pathogens of prostatitis were researched, culture positivity and PCR positivity were $12(11 \%)$ and $37(35 \%)$ cases, respectively. According to the culture results, the most frequently identified pathogens were E. coli with $48 \%$, E. faecium with $20 \%$, and S. epidermidis and S. haemolyticus with $13 \%$, which revealed equivalent results with our study. However, considering PCR re- sults when our study, which is community-acquired (outpatient clinic patients), is compared with this hospital-acquired study, it was observed that all pathogens except $U$. urealyticum were detected at higher ratios (8). This gives rise to the thought that in hospital-acquired prostatitis different to community-acquired disease, intracellular agents may be observed more frequently, which reveals the importance of PCR analysis, relative to this.

\section{CONCLUSION}

In a Turkish population, category 2 patients constitute $7 \%$ of all chronic prostatitis patients which is consistent with the NIH classification of prostatitis data. However, there are significant differences with the frequency and distribution of reproduced pathogens.

Ethics Committee Approval: Authors declared that the research was conducted according to the principles of the World Medical Association Declaration of Helsinki "Ethical Principles for Medical Research Involving Human Subjects", (amended in October 2013).

Informed Consent: Written informed consent was obtained from patients who participated in this study.

Peer-review: Externally peer-reviewed.

Author Contributions: Concept - E.A., B.Ç.; Design - R.G.; Supervision E.A., B.Ç.; Resources - B.Ç., R.G.; Materials - M.G.A.; Data Collection and Processing - M.G.A., E.A.; Analysis and Interpretation - B.Ç.; Literature Search - M.G.A., E.A.; Writing Manuscript - E.A., M.G.A.; Critical Review - R.G., B.Ç.

Conflict of Interest: The authors have no conflict of interest to declare.

Financial Disclosure: The authors declared that this study has received no financial support.

\section{REFERENCES}

1. Arda E, Cakiroglu B, Tas T, Ekici S, Uyanik BS. Use of the UPOINT Classification in Turkish Chronic Prostatitis or Chronic Pelvic Pain Syndrome Patients. Urology 2016; 97: 227-31. [CrossRef]

2. Meares EM, Stamey TA. Bacteriologic localization patterns in bacterial prostatitis and urethritis. Invest Urol 1968; 5: 492-518.

3. Collins MM, Stafford RS, O'Leary MP, Barry MJ. How common is prostatitis? A national survey of physician visits. J Urol 1998; 159: 1224-8. [CrossRef]

4. Bartoletti R, Cai T, Mondaini N, Dinelli N, Pinzi N, Pavone C, et al. Prevalence, incidence estimation, risk factors and characterization of chronic prostatitis/chronic pelvic pain syndrome in urological hospital outpatients in Italy: results of a multicenter case-control observational study. J Urol 2007; 178: 2411-5. [CrossRef]

5. Roberts RO, Lieber MM, Rhodes T, Girman CJ, Bostwick DG, Jacobsen SJ. Prevalence of a physician-assigned diagnosis of prostatitis: the Olmsted County Study of Urinary Symptoms and Health Status Among Men. Urology 1998; 51: 578-84. [CrossRef]

6. Skerk V, Krhen I, Schonwald S, Cajic V, Markovinovic L, Roglic S, et al. The role of unusual pathogens in prostatitis syndrome. Int J Antimicrob Agents 2004; 24 Suppl 1: S53-6. [CrossRef]

7. Schaeffer AJ. Prostatitis: US perspective. Int J Antimicrob Agents 1999; 11: 205-11. [CrossRef]

8. Choi YS, Kim KS, Choi SW, Kim S, Bae WJ, Cho HJ, et al. Microbiological etiology of bacterial prostatitis in general hospital and primary care clinic in Korea. Prostate Int 2013; 1: 133-8. [CrossRef]

9. Dogan AN, Cakiroglu B, Hazar Al, Gozukucuk R, Uyanik BS. Can red cell distribution width and mean platelet volume serve as a marker for chronic prostatitis? Int J Clin Exp Med 2016; 9: 250-4.

10. Krieger JN, Nyberg L Jr, Nickel JC. NIH consensus definition and classification of prostatitis. JAMA. 1999; 282: 236-7. [CrossRef] 
11. Giubilei G, Mondaini N, Crisci A, Raugei A, Lombardi G, Travaglini F, Del Popolo G, Bartoletti R. The Italian version of the National Institutes of Health Chronic Prostatitis Symptom Index. Eur Urol 2005; 47: 805-11. [CrossRef]

12. Krieger J. Prostatitis, epididymitis and orchitis. $6^{\text {th }}$ ed. Philadelphia: Elseivier's Health Sciences; 2005.

13. Stevermer JJ, Easley SK. Treatment of prostatitis. Am Fam Physician 2000; 61: 3015-22, 3025-6.

14. Nickel JC, Shoskes D, Wang Y, Alexander RB, Fowler JE, Jr., Zeitlin S, et al. How does the pre-massage and post-massage 2-glass test compare to the Meares-Stamey 4-glass test in men with chronic prostatitis/chronic pelvic pain syndrome? J Urol 2006; 176: 119-24. [CrossRef]

15. Lobel B, Rodriguez A. Chronic prostatitis: what we know, what we do not know, and what we should do! World J Urol 2003; 21: 57-63. [CrossRef]

16. Heras-Canas V, Gutierrez-Soto B, Serrano-Garcia ML, Vazquez-Alonso F, Navarro-Mari JM, Gutierrez-Fernandez J. Chronic bacterial prostatitis. Clinical and microbiological study of 332 cases. Med Clin (Barc) 2016; 147: 144-7. [CrossRef]
17. Ouzounova-Raykova V, Ouzounova I, Mitov I. May Chlamydia trachomatis be an aetiological agent of chronic prostatic infection? Andrologia 2010; 42: 176-81. [CrossRef]

18. Guo H, Lu G, Zhang $Q$, Xiong X. Detection of chlamydia trachomatis by polymerase chain reaction assay in nonbacterial prostatitis. Chin Med J (Engl) 1997; 110: 177-9.

19. Baseman JB, Tully JG. Mycoplasmas: sophisticated, reemerging, and burdened by their notoriety. Emerg Infect Dis 1997; 3: 21-32. [CrossRef]

20. Uuskula A, Kohl PK. Genital mycoplasmas, including Mycoplasma genitalium, as sexually transmitted agents. Int J STD AIDS 2002; 13 : 79-85. [CrossRef]

21. Keck C, Gerber-Schafer C, Clad A, Wilhelm C, Breckwoldt M. Seminal tract infections: impact on male fertility and treatment options. Hum Reprod Update 1998; 4: 891-903. [CrossRef]

22. Potts JM, Sharma R, Pasqualotto F, Nelson D, Hall G, Agarwal A. Association of ureaplasma urealyticum with abnormal reactive oxygen species levels and absence of leukocytospermia. J Urol 2000; 163: 1775-8. [CrossRef] 